УДК 581.55(571.122)

doi: $10.17223 / 19988591 / 35 / 5$

\author{
Г.С. Таран ${ }^{1}$ В.Н. Тюрин², А.П. Дьяченко ${ }^{3}$ \\ 'Западно-Сибирский филиал Института леса им. В.Н. Сукачева \\ СО РАН, г. Новосибирск, Россия \\ ${ }^{2}$ Сургутский государственный университет, г. Сургут, Россия \\ ${ }^{3}$ Уральский государственный педагогический университет, г. Екатеринбург, Россия

\section{Новое местонахождение лопарскоивняков (Carici aquatilis-Salicetum lapponum Taran 1993, Alnetea glutinosae) в Западной Сибири}

\begin{abstract}
Новое местонахождение ивняков с доминированием Salix lapponum $L$. обнаружено в пойме р. Ягмунъягун в 37 км к востоку от г. Сургута, 6119'23" с.ш., 7412'01" в.д. (Сургутский район Ханты-Мансийского автономного округа). Цель статьи - дать детальную синтаксономическую и ландмафтную характеристику этим оригинальным сообществам, слабо отраженным 6 геоботанической литературе. В классификации Браун-Бланке ягмунъягунские ивняки опознаны как ассоџиация Carici aquatilis-Salicetum lapponum Taran 1993 (союз Salicion cinereae Th. Müller et Görs ex Passarge 1961, порядок Salicetalia auritae Doing 1962, класс Alnetea glutinosae Br.-Bl. et Tx. ex Westhoff et al. 1943). Изученные лопарскоивняки разделяются на две субассоциации: C. a.-S. l. typicum Taran 1993 (вариант Carex lasiocarpa) и Carici aquatilis-Salicetum lapponum juncetosum filiformis Taran, Tyurin et Dyachenko subass. nov.; диагностические виды последней - Juncus filiformis, Gentiana pneumonanthe, Phalaroides arundinacea. Средняя высота ивы в иенозах субасс. C. a.-S. I. juncetosum filiformis - 1,5 м, среднее общее проективное покрытие ивы - 24\%, травостоя $48 \%$, напочвенных мхов - 17\%, средняя видовая насыщенность сосудистыми -

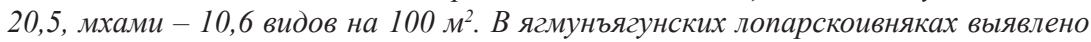
44 вида сосудистых растений, 1 вид печеночников и 27 видов мхов, в том числе Sphagnum inundatum, новый для бриофлоры Ханты-Мансийского автономного округа. Лопарскоивняки субасс. Carici aquatilis-Salicetum lapponum juncetosum filiformis располагаются на уровнях затопления 90-95\% обеспеченности.

Ключевые слова: кустарниковые ивняки; Salix lapponum; бриофлора; синтаксономия; пойменная растительность; подзона средней тайги.
\end{abstract}

\title{
Введение
}

Ива лопарская (Salix lapponum L.) - характерный болотный вид [1], тесно связанный с торфяными болотами [2]. Несмотря на широкое распространение в Западной Сибири, в подзонах средней и южной тайги она обычно отмечается как малообильный вид и лишь в некоторых работах указывается как доминант и содоминант редких вариантов болот в поймах Васюгана и Тыма $[3,4]$. 
В 1986-1988 гг. сообщества с доминированием Salix lapponum, или лопарскоивняки, изучены в пойме р. Оби на севере Томской области и описаны как эколого-флористическая ассоциация Carici aquatilis-Salicetum lapponum Taran 1993, отнесенная к классу эвтрофных лесных и кустарниковых болот Alnetea glutinosae [5]. В дальнейшем ассоциация отмечена в пойме Ваха [6] и пойме Оби в ближайших окрестностях г. Сургута [7-9].

До сих пор сообщества ивы лопарской, характерные для труднодоступных заболоченных участков притеррасной поймы Оби в пределах подзоны средней тайги, остаются почти не изученными. Информация о них отсутствует в монографии «Растительный покров Западно-Сибирской равнины» [10] и в недавней работе, посвященной классификации западносибирских болот [11].

Несколько лет назад лопарскоивняки найдены на значительном удалении от г. Сургута в виде необычного лугово-болотного варианта, занимающего значительные площади поймы. Цель статьи - дать детальную синтаксономическую и ландшафтную характеристику этим оригинальным растительным сообществам, слабо отраженным в геоботанической литературе.

\section{Материалы и методики исследования}

По природным условиям район исследований относится к подзоне средней тайги [10]. Материал собран в первой декаде сентября 2011 г. в пойме малой реки Ягмунъягун, впадающей с правого берега в р. Тромъеган в точке с координатами $61^{\circ} 15^{\prime} 04^{\prime \prime}$ с.ш., $74^{\circ} 12^{\prime} 24^{\prime \prime}$ в.Д. Далее этот участок поймы, расположенный в 37 км на восток от г. Сургута, будем называть Ягмунъягунским ключевым полигоном. Центр полигона имеет координаты 61 $19^{\circ} 23^{\prime \prime}$ с.ш., 7412'01" в.Д.

В гидрологическом отношении полигон расположен в объединенной пойме Оби, Тромъегана и Ягмунъягуна. В период половодий Обь подпирает воды Тромъегана далеко вверх по течению; средняя многолетняя длина подпорного участка в нижнем течении Тромъегана составляет 179 км [12]. В геоморфологическом смысле полигон приурочен к участкам древнего меандрового пояса сниженной ступени первой надпойменной террасы Оби [13], которую вслед за Г.В. Обедиентовой [14] будем называть голоценовой. Почвы определялись по [15], гидрологическая терминология приводится по [16].

Геоботанические описания (оп.) выполнялись на учетных площадках

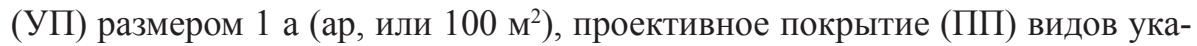
зывалось в процентах, низкие значения ПП - в баллах: $\mathrm{r}-$ не более $0,01 \%$; +- более 0,01 , но менее $0,3 \%$. ПП мхов указывалось только для легко распознаваемых в поле видов. Обработка описаний велась с помощью интегрированной ботанической информационной системы IBIS [17]. Отнесение сообществ к синтаксонам проводилось на основе эколого-флористической классификации Браун-Бланке $[18,19]$. Авторы описаний и коллекторы 
мхов - Г.С. Таран и В.Н. Тюрин, образцы мхов определил А.П. Дьяченко. Виды сосудистых растений приводятся по С.К. Черепанову [20], мхов - по M.S. Ignatov et al. [21]. Сборы мхов хранятся в Западно-Сибирском филиале Института леса СО РАН (г. Новосибирск).

\section{Очерк растительности района исследований}

Ягмунъягунский ключевой полигон представляет собой выровненное пространство с небольшими перепадами высот. Поверхности среднего высотного уровня заняты сообществами ивы лопарской, более низкие - болотистыми лугами и травяными болотами (рис. 1). Наиболее обычные доминанты лугово-болотной растительности - Calamagrostis purpurea, Carex acuta, Carex aquatilis, Comarum palustre, Carex vesicaria.

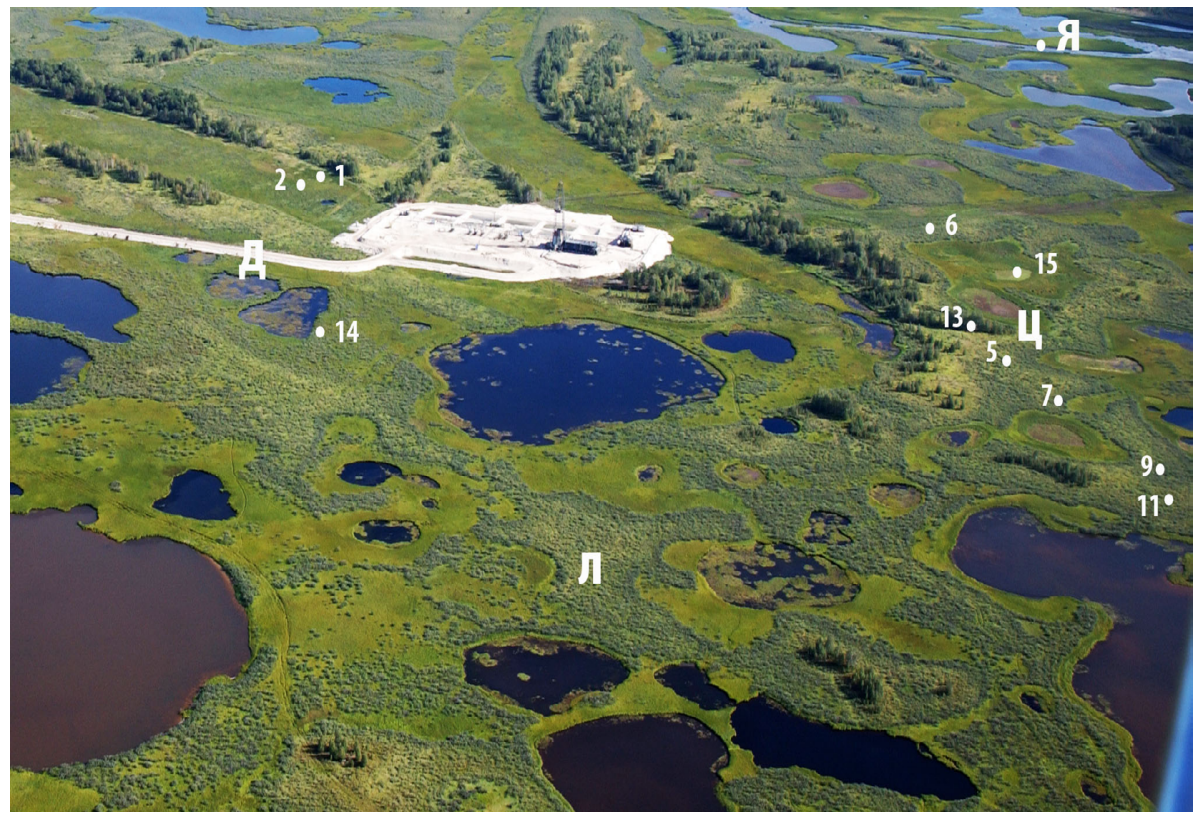

Рис. 1. Вид на Ягмунъягунский ключевой полигон с борта самолета (10.09.2003 г., фото В.Н. Тюрина). Номера точек соответствуют полевым номерам описаний, приведенным в текстовой характеристике полигона и в таблице. Прочие обозначения: Д - насыпная дорога к песчаной отсыпке (промышленному объекту); Л - крупный контур одного

из лопарскоивняков; Ц - центр ключевого полигона, Я - русло р. Ягмунъягун

[Fig. 1. View on the Yagmunyagun key plot area from a plane (10.09.2003, photo by VN Tyurin). Numbers of the points correspond to the releve field numbers cited in the plot area text characteristic and the table. Other symbols: Д - Sandy road to the sandy embankment (industrial object); Л - Large contour of a downy willow scrub;

Ц - The key plot area center; $Я$ - The Yagmunyagun River channel] 
Облесенность полигона невелика. На гребнях слабо выраженных в рельефе пойменных грив изредка отмечаются небольшие пятна сосняков-жердняков, пройденных низовыми пожарами, но наиболее обычны влажные березовые леса. Для примера приведем описание такого сообщества.

Оп. 13 ГТ (Г.С. Таран), 08.09.2011, площадь УП 100 м². Березняк разнотравно-злаково-долгомошный. Состав древостоя 10Б, общее проективное покрытие (ОПП) - 40\%, средняя высота - 17 м. На УП насчитано 12 стволов, среднеарифметический диаметр 19 см, максимальный - 35 см. ОПП подлеска $0,5 \%$, высота $0,9-1,5$ м. ОПП травостоя $30 \%$, высота 55 см. ОПП напочвенных мхов 50\%, толщина мохового покрова $8 \mathrm{~cm}$. Почва аллювиальная оподзоленная.

Видовой состав (здесь и далее ПП видов указано в \%): Betula pubescens 40, Salix lapponum 0,5, Pinus sylvestris (juv.) +, Calamagrostis purpurea 17, Sanguisorba officinalis 7, Poa angustifolia 3, Hieracium umbellatum 2, Juncus filiformis 1, Carex juncella 0,7, Carex acuta 0,3, Hylotelephium triphyllum 0,5, Gentiana pneumonanthe 0,3, Chamaenerion angustifolium + . Напочвенные мхи: Polytrichum commune 40, Ceratodon purpureus 9, Polytrichum juniperinum 0,5, Climacium dendroides 0,5, Calliergonella lindbergii + , Drepanocladus aduncus + , Pohlia nutans + .

В синтаксономическом отношении этот фитоценоз можно отнести к березовой фации (betulosum pubescentis) субассоциации Spiraeo salicifoliaePopuletum tremulae franguletosum alni Taran 1993 [22]. От сообществ субассоциации, изученных в Томской области, данное описание отличается более низкой видовой насыщенностью (13 видов сосудистых против 16-37 видов на $\left.100 \mathrm{M}^{2}\right)$.

В заторфованных староречьях Ягмунъягуна отмечаются осоковые и осоково-сабельниковые болота. Приведем два примера.

Оп. 1 ВТ (В.Н. Тюрин), 08.09.2011, площадь УП 100 м², площадь фитоценоза 7 а. Пузырчатоосоковое болото. Почва аллювиальная болотная иловато-торфяно-глеевая, толщина торфа 22-32 см, ниже залегает сырой песок. ОПП травостоя 50\%, высота 70 см. ОПП ветоши $75 \%$, ОПП мхов $40 \%$. Видовой состав: Carex vesicaria 40, Agrostis stolonifera 7, Carex aquatilis 3, Comarum palustre 3, Ranunculus lingua 0,5, Calamagrostis neglecta 0,5, Naumburgia thyrsiflora 0,5, Stellaria palustris + , Galium palustre + , Epilobium palustre r. Напочвенные мхи: Sphagnum obtusum 38, Calliergon cordifolium 1, Drepanocladus aduncus 1.

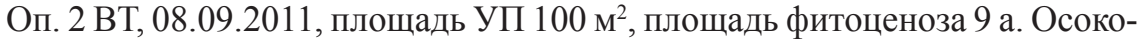
во-сабельниковое болото. Почва аллювиальная болотная иловато-торфяная, торфяной горизонт толщиной 52-67 см, мокрый. ОПП травостоя 50\%, высота 80/35 см. ОПП мхов 75\%. Видовой состав: Salix lapponum 1, Coтаrum palustre 40, Carex lasiocarpa 10, Carex aquatilis 3, Calamagrostis neglecta 3, Carex rostrata 2, Agrostis stolonifera 1, Carex omskiana 0,5, Carex chordorrhiza + , Eriophorum polystachion + , Equisetum fluviatile +, Naumburgia thyrsiflora + , 
Stellaria palustris +, Galium palustre +. Напочвенные мхи: Sphagnum flexиоsum 72, Sphagnum squarrosum 2, Sphagnum subsecundum 1, Calliergon cordifolium + .
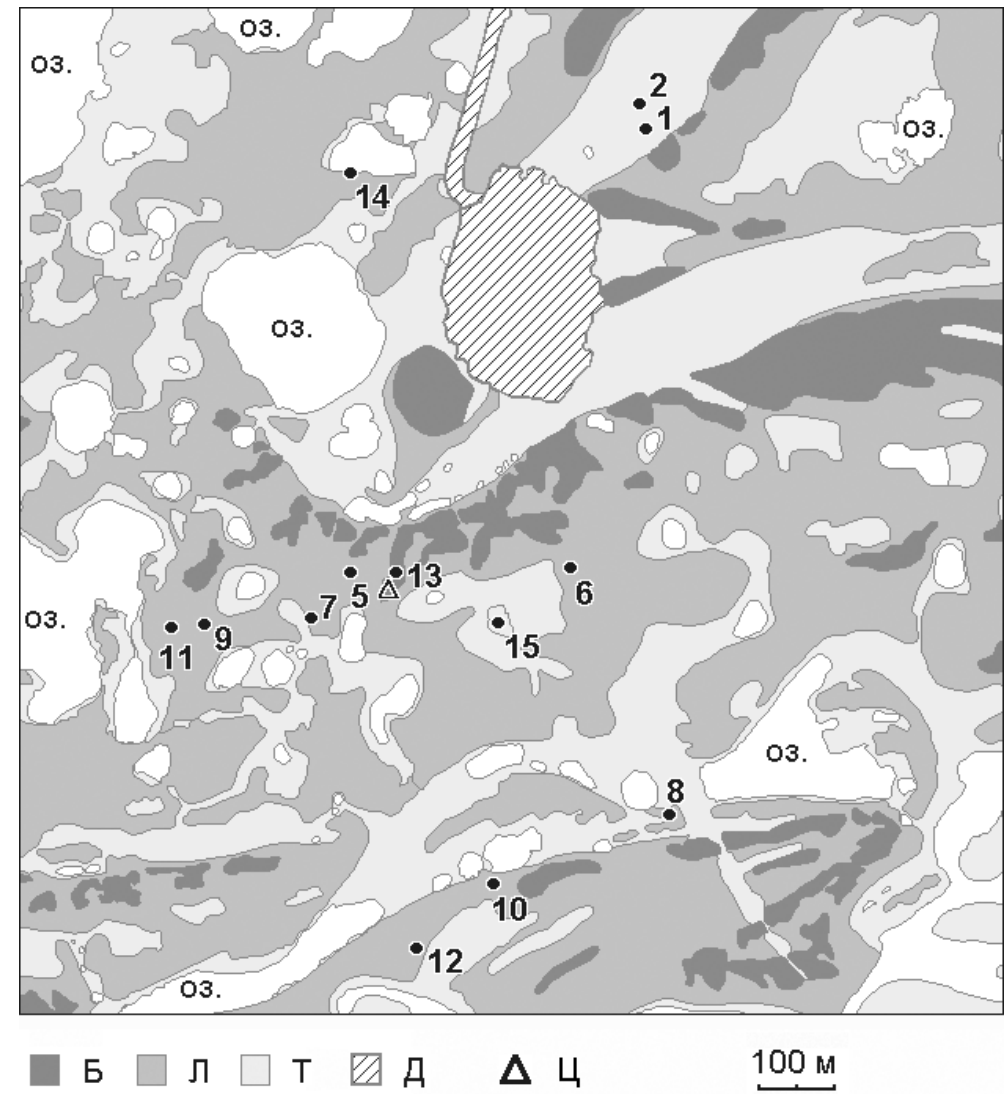

Pис. 2. Пространственная структура растительности Ягмунъягунского ключевого полигона. Номера точек соответствуют полевым номерам описаний. Прочие обозначения: Б - березовые леса; Л - лопарскоивняки; Т - болотистые луга и травяные болота; Д - насыпная дорога и песчаная отсыпка под промышленный

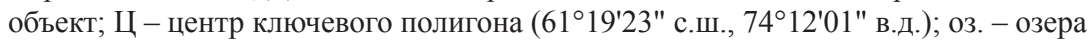

[Fig. 2. Space structure of the Yagmunyagun key plot area vegetation.

Numbers of the points correspond to the relevé field numbers. Other symbols: $\mathbf{6}$ - Birch forests;

T - Swampy meadows and fens; Л - Downy willow scrubs; Д - Sandy road and sandy embankment for industrial object; Ц - The key plot area center $\left(61^{\circ} 19^{\prime} 23^{\prime \prime} \mathrm{N}, 74^{\circ} 12^{\prime} 01{ }^{\prime \prime E}\right) ;$ o3. - Lakes]

Значительные площади на ключевом полигоне занимают пойменные озера, на мелководьях которых обычны заросли Sparganium emersum. Часть озер к осени пересыхает, и на их днищах развиваются эксплерентные группировки, характерные для внутрипойменных соров [23].

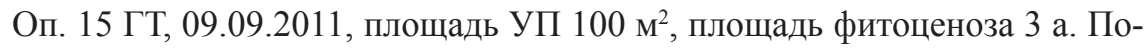
левицево-лисохвостовый луг на илистом днище пересохшего водоема. ОПП 
травостоя 90\%, высота 20/4 см, ОПП мхов 10\%. Видовой состав: Alopecurus aequalis 40 (высота 15-20 см), Agrostis stolonifera 40 (высота 4 см), Sparganium emersum 10 (высота $20 \mathrm{~cm}$ ), Eleocharis acicularis 3, Ranunculus gmelinii 2, Rorippa amphibia 0,5, Eleocharis palustris + , Callitriche palustris + , Sium latifolium +, Alisma plantago-aquatica +, Potamogeton gramineus f. terrestris + , Persicaria minor r, Ranunculus lingua r, Elatine hydropiper r. Mох на почве: Drepanocladus aduncus 10.

Общая площадь Ягмунъягунского ключевого полигона равна 162,4 га. Соотношение площадей различных типов растительных сообществ, пойменных водоемов и песчаных отсыпок на ключевом полигоне выражается следующими цифрами: лопарскоивняки - 43,4\% (70,4 га); болотистые луга и травяные болота - 30,8\% (50,1 га); березовые леса - 7,7\% (12,5 га); водоемы - 14,9\% (24,2 га); насыпная дорога и песчаная отсыпка под промышленный объект - 3,2\% (5,2 га). Карта растительности составлена на основе перспективных аэроснимков В.Н. Тюрина (см. рис. 1) и космоснимка высокого разрешения, предоставленного в свободное использование интернетсервисом Google Earth (рис. 2).

\section{Результаты исследования и обсуждение}

Изученные ценозы лопарскоивняков можно уверенно отнести к описанной на севере Томской области эколого-флористической ассоциации Carici aquatilis-Salicetum lapponum Taran 1993, входящей в союз Salicion cinereae Th. Müller et Görs ex Passarge 1961, порядок Salicetalia auritae Doing 1962, класс Alnetea glutinosae Br.-Bl. et Tx. ex Westhoff et al. 1943 [5] (таблица).

\section{Лопарскоивняки Ягмунъягунского ключевого полигона (acc. Carici aquatilis-Salicetum lapponum Taran 1993) \\ [Downy willow scrubs of the Yagmunyagun key plot area (ass. Carici aquatilis-Salicetum lapponum Taran 1993)]}

\begin{tabular}{|c|c|c|c|c|c|c|c|c|c|c|}
\hline $\begin{array}{l}\text { Порядковый номер описания } \\
\text { [Successive relevé number] }\end{array}$ & 1 & 2 & $3 *$ & 4 & 5 & 6 & 7 & 8 & 9 & $\begin{array}{l}\Pi_{2-9} \\
\mathrm{C}_{2-9}\end{array}$ \\
\hline $\begin{array}{l}\text { Полевой номер описания } \\
\text { [Field relevé number] }\end{array}$ & 14 & 5 & 6 & 7 & 8 & 9 & 10 & 11 & 12 & \\
\hline $\begin{array}{l}\text { Дата описания в } 2011 \text { г., день/месяц } \\
\text { [Date of a relevé in 2011, day/month] }\end{array}$ & $8 / 9$ & $5 / 9$ & $5 / 9$ & $7 / 9$ & $6 / 9$ & $7 / 9$ & $7 / 9$ & $8 / 9$ & $7 / 9$ & \\
\hline $\begin{array}{l}\text { Площадь УП, }{ }^{2} \\
\left.\text { [Plot size, } \mathrm{m}^{2}\right\rceil\end{array}$ & 100 & 100 & 100 & 100 & 100 & 100 & 100 & 100 & 100 & \\
\hline $\begin{array}{l}\text { Уклон поверхности УП, градусы } \\
\text { [Plot surface inclination, degrees] }\end{array}$ & 0 & $1-3$ & 0 & 0 & 0 & 0 & 3 & 0 & $1-2$ & \\
\hline $\begin{array}{l}\text { Высота ивы минимальная, м } \\
\text { [Willow minimum height, m] }\end{array}$ & 1,0 & 1,5 & 0,8 & 1,2 & 1,3 & 1,3 & 1,0 & 1,0 & 1,3 & \\
\hline $\begin{array}{l}\text { Высота ивы максимальная, м } \\
\text { [Willow maximum height, m] }\end{array}$ & 1,8 & 1,9 & 2,2 & 2,5 & 2,1 & 1,8 & 1,5 & 1,5 & 2,0 & \\
\hline $\begin{array}{l}\text { Высота ивы средняя, м } \\
\text { [Willow mean height, m] }\end{array}$ & 1,4 & 1,6 & 1,3 & 1,6 & 1,7 & 1,6 & 1,2 & 1,1 & 1,7 & \\
\hline
\end{tabular}


Пр од о л же н и е т а б ли цы [Table (cont.)]

\begin{tabular}{|c|c|c|c|c|c|c|c|c|c|c|}
\hline $\begin{array}{l}\text { Порядковый номер описания } \\
\text { [Successive relevé number] }\end{array}$ & 1 & 2 & $3 *$ & 4 & 5 & 6 & 7 & 8 & 9 & $\begin{array}{l}\Pi_{2-9} \\
\mathrm{C}_{2-9}\end{array}$ \\
\hline $\begin{array}{l}\text { ОПП ивы, \% } \\
\text { [Willow cover, \%] }\end{array}$ & 25 & 25 & 25 & 25 & 35 & 25 & 17 & 15 & 25 & \\
\hline $\begin{array}{l}\text { OПП травостоя, \% } \\
\text { [Field layer cover, \%] }\end{array}$ & 60 & 25 & 35 & 40 & 70 & 30 & 60 & 60 & 60 & \\
\hline $\begin{array}{l}\text { ОПП ветоши, \% } \\
{[\text { Dead grass cover, \%] }}\end{array}$ & 50 & - & 75 & 45 & - & 50 & 50 & 30 & 50 & \\
\hline $\begin{array}{l}\text { ОПП мхов на почве, \% } \\
\text { [Ground-layer moss cover, \%] }\end{array}$ & 35 & 15 & 15 & 10 & 20 & 15 & 25 & 30 & 7 & \\
\hline $\begin{array}{l}\text { В том числе ОПП сфагнов, \% } \\
\text { [Including Sphagna cover, \%] }\end{array}$ & 1 & 0 & 1 & $r$ & 1,5 & 0 & + & 0 & 1 & \\
\hline $\begin{array}{l}\text { Число видов сосудистых } \\
\text { [Number of vascular plant species] }\end{array}$ & 14 & 25 & 20 & 23 & 18 & 15 & 23 & 24 & 16 & \\
\hline $\begin{array}{l}\text { Число видов мхов } \\
\text { [Number of moss species] }\end{array}$ & 6 & 11 & 11 & 21 & 7 & 14 & 6 & 9 & 6 & \\
\hline $\begin{array}{l}\text { Средняя высота затопления УП, см } \\
\text { [Flood mean height in a plot, cm] }\end{array}$ & - & - & - & 40 & 52 & - & 35 & 0 & 53 & \\
\hline $\begin{array}{l}\text { Глубина почвенной прикопки, см } \\
\text { [Soil trenchlet depth, cm] }\end{array}$ & 35 & 63 & 53 & 60 & 75 & 70 & 40 & 60 & 70 & \\
\hline $\begin{array}{l}\text { Толщина торфа, см } \\
\text { [Thickness of peat, cm] }\end{array}$ & 77 & - & - & - & - & - & - & - & - & \\
\hline $\begin{array}{l}\text { Толщина оторфованной подстилки, см } \\
\text { [Thickness of peaty litter, cm] }\end{array}$ & - & 9 & 4 & 4 & 11 & 6 & 4 & 5 & 6 & \\
\hline $\begin{array}{l}\text { Нижняя граница концентрации } \\
\text { основной массы корней, см } \\
\text { [Lower border of main root mass } \\
\text { concentration, cm] }\end{array}$ & - & 21 & 23 & 18 & 26 & 14 & 15 & 18 & 19 & \\
\hline \multicolumn{11}{|c|}{ Д. в. acc. [D. s. of ass.] Carici aquatilis-Salicetum lapponum } \\
\hline Salix lapponum & 25 & 25 & 25 & 25 & 35 & 25 & 17 & 15 & 25 & $\mathrm{~V}^{3-3}$ \\
\hline Carex aquatilis & 18 & . & + & $\cdot$ & 10 & + & . & . & + & III \\
\hline \multicolumn{11}{|c|}{ Д. в. варианта [D. s. of variant] Carex lasiocarpa } \\
\hline Carex lasiocarpa & 9 & . & . & . & . & . & . & . & . & . \\
\hline Carex rostrata & 6 & . & . & . & . & . & . & . & . & . \\
\hline \multicolumn{11}{|c|}{ Д. в. субасс. [D. s. of subass.] C. a.-S. l. juncetosum filiformis } \\
\hline Juncus filiformis & . & + & + & 1 & 7 & $\mathrm{r}$ & 2 & 5 & 3 & $\mathrm{~V}^{+-1}$ \\
\hline Gentiana pneumonanthe & . & + & $\mathrm{r}$ & + & . & + & 1 & 1 & + & $\mathrm{V}$ \\
\hline Phalaroides arundinacea & . & 10 & 7 & + & . & 5 & . & 2 & . & $\mathrm{IV}^{-1}$ \\
\hline \multicolumn{11}{|c|}{ Д. в. класса [D. s. of class] Alnetea glutinosae } \\
\hline Comarum palustre & 33 & 1 & 7 & 3 & 40 & 8 & 6 & $\mathrm{r}$ & 23 & $\mathrm{~V}^{1-2}$ \\
\hline Galium palustre & 1 & 5 & + & 3 & 4 & 2 & + & 3 & 1 & $\mathrm{~V}^{1-1}$ \\
\hline Carex acuta & . & 1 & 1 & + & 3 & 5 & 7 & 0,5 & 15 & $\mathrm{~V}^{1-1}$ \\
\hline Carex vesicaria & . & + & 0,3 & + & 1 & 2 & $\mathrm{r}$ & 0,5 & + & $\mathrm{V}^{+-1}$ \\
\hline Naumburgia thyrsiflora & 1 & . & 0,5 & + & 7 & + & . & 2 & 10 & $\mathrm{IV}^{-1}$ \\
\hline \multicolumn{11}{|c|}{ Д. в. класса [D. s. of class] Scheuchzerio-Caricetea } \\
\hline Stellaria palustris & $\mathrm{r}$ & + & $\mathrm{r}$ & + & + & + & $\mathrm{r}$ & + & $\mathrm{r}$ & $\mathrm{V}$ \\
\hline Calamagrostis neglecta & 5 & . & . & . & 1 & . & . & . & + & II \\
\hline
\end{tabular}


О к о н ч а н и е т а б ли цы [Table (end)]

\begin{tabular}{|l|c|c|c|c|c|c|c|c|c|c|}
\hline $\begin{array}{c}\text { Порядковый номер описания } \\
\text { [Successive relevé number] }\end{array}$ & 1 & 2 & $3 *$ & 4 & 5 & 6 & 7 & 8 & 9 & $\begin{array}{c}\Pi_{2-9} \\
\mathrm{C}_{2-9}\end{array}$ \\
\hline Agrostis stolonifera & 3 &. & $\mathrm{r}$ & + & 5 &. & 3 & + & 2 & $\mathrm{IV}^{-1}$ \\
\hline Lythrum salicaria & 1 & + & $\mathrm{r}$ & 0,5 &. &. & + & + &. & $\mathrm{IV}$ \\
\hline Carex omskiana & 0,5 & + &. & + &. &. &. &. &. & $\mathrm{II}$ \\
\hline Carex juncella &. &. & 1 & + &. &. &. &. &. & $\mathrm{II}$ \\
\hline
\end{tabular}

Д. в. класса [D. s. of class] Molinio-Arrhenatheretea

\begin{tabular}{|l|c|c|c|c|c|c|c|c|c|c|}
\hline Lysimachia vulgaris &. & + & + & 0,5 & 1 & + & 1 & + & 4 & $\mathrm{~V}^{+-1}$ \\
\hline Veronica longifolia &. & + & + & + & + & + & 1 & 1 & 1 & $\mathrm{~V}^{+-1}$ \\
\hline Thalictrum simplex &. & 1 & 0,5 & + & + & + & 0,5 & 1 &. & $\mathrm{~V}^{+-1}$ \\
\hline Sanguisorba officinalis &. &. &. & + &. &. & 18 & 30 & + & $\mathrm{III}$ \\
\hline Galium boreale &. & $\mathrm{r}$ &. &. &. &. & 12 & 0,5 & $\mathrm{r}$ & $\mathrm{III}$ \\
\hline Caltha palustris &. & $\mathrm{r}$ & $\mathrm{r}$ & $\mathrm{r}$ &. &. & $\mathrm{r}$ &. &. & $\mathrm{III}$ \\
\hline Hieracium umbellatum &. & $\mathrm{r}$ &. &. &. &. & $\mathrm{r}$ & + &. & $\mathrm{II}$ \\
\hline
\end{tabular}

Прочие виды [Other species]

\begin{tabular}{|l|c|c|c|c|c|c|c|c|c|c|}
\hline Calamagrostis purpurea &. & 5 & 20 & 30 & 5 & 10 & 27 & 15 & 7 & $\mathrm{~V}^{2-3}$ \\
\hline Ptarmica cartilaginea &. & + &. & $\mathrm{r}$ & $\mathrm{r}$ & $\mathrm{r}$ & $\mathrm{r}$ & + &. & $\mathrm{IV}$ \\
\hline Ranunculus repens &. & 3 &. & + & $\mathrm{r}$ &. & + & 0,5 &. & $\mathrm{IV}$ \\
\hline Betula pubescens (juv.) &. &. & $\mathrm{r}$ &. &. &. & $\mathrm{r}$ & $\mathrm{r}$ &. & $\mathrm{II}$ \\
\hline Poa angustifolia &. &. &. &. &. &. & 0,5 & 3 &. & $\mathrm{II}$ \\
\hline Rhinanthus serotinus &. & + &. &. &. &. &. & + &. & II \\
\hline \multicolumn{7}{|c}{ Мхи [Mosses] }
\end{tabular}

\begin{tabular}{|l|c|c|c|c|c|c|c|c|c|c|}
\hline Calliergonella lindbergii & $\mathrm{d}^{28}$ & $\mathrm{~d}^{+}$ & $\mathrm{d}^{0,5}$ & $\mathrm{ed}$ & $\mathrm{d}$ & $\mathrm{d}^{+}$ & $\mathrm{d}^{8}$ & $\mathrm{~d}$ & $\mathrm{~d}^{0,5}$ & $\mathrm{~V}$ \\
\hline Drepanocladus aduncus &. & $\mathrm{d}^{10}$ & $\mathrm{~d}^{2}$ & $\mathrm{~d}$ & $\mathrm{~d}^{10}$ & $\mathrm{ed}^{10}$ & $\mathrm{~d}^{3}$ & $\mathrm{~d}^{3}$ & $\mathrm{~d}$ & $\mathrm{~V}^{1-2}$ \\
\hline Climacium dendroides &. & $\mathrm{d}^{+}$ & $\mathrm{d}^{1}$ & $\mathrm{ed}$ & $\mathrm{d}^{1}$ & $\mathrm{~d}^{+}$ & $\mathrm{d}^{3}$ & $\mathrm{~d}^{1,5}$ &. & $\mathrm{~V}^{+-1}$ \\
\hline Drepanocladus polygamus & $\mathrm{d}^{2}$ & $\mathrm{~d}$ & $\mathrm{~d}$ & $\mathrm{ed}$ &. & $\mathrm{ed}$ &. & $\mathrm{d}$ & $\mathrm{d}$ & $\mathrm{IV}$ \\
\hline Pohlia bulbifera &. & $\mathrm{d}$ &. & $\mathrm{d}$ &. & $\mathrm{d}$ & $\mathrm{d}$ & $\mathrm{d}^{2}$ &. & $\mathrm{IV}$ \\
\hline Aulacomnium palustre &. & $\mathrm{d}^{\mathrm{r}}$ & $\mathrm{d}$ & $\mathrm{e}$ &. & $\mathrm{d}$ &. & $\mathrm{d}$ &. & $\mathrm{IV}$ \\
\hline Calliergon cordifolium & $\mathrm{d}^{2}$ &. & $\mathrm{~d}^{3}$ & $\mathrm{~d}$ &. & $\mathrm{~d}$ &. &. & $\mathrm{~d}^{1}$ & $\mathrm{III}$ \\
\hline Pohlia nutans &. & $\mathrm{d}$ &. & $\mathrm{d}$ &. & $\mathrm{d}$ &. & $\mathrm{d}^{22}$ &. & $\mathrm{III}$ \\
\hline Polytrichastrum longisetum &. & $\mathrm{d}$ &. & $\mathrm{d}$ &. & $\mathrm{d}^{\mathrm{r}}$ &. & $\mathrm{d}^{\mathrm{r}}$ &. & $\mathrm{III}$ \\
\hline Polytrichum commune &. &. &. & $\mathrm{d}$ &. & $\mathrm{d}^{\mathrm{r}}$ & $\mathrm{d}^{7}$ & $\mathrm{~d}^{0,5}$ &. & $\mathrm{III}$ \\
\hline Fontinalis hypnoides &. &. &. & $\mathrm{ed}$ & $\mathrm{e}$ & $\mathrm{e}$ &. &. & $\mathrm{e}^{1}$ & $\mathrm{III}$ \\
\hline Calliergon giganteum &. &. &. & $\mathrm{d}$ & $\mathrm{d}^{10}$ & $\mathrm{~d}$ &. &. &. & $\mathrm{II}$ \\
\hline Leskea polycarpa &. &. & $\mathrm{d}$ & $\mathrm{e}$ &. & $\mathrm{e}$ &. &. &. & $\mathrm{II}$ \\
\hline Sphagnum centrale &. &. &. &. & $\mathrm{d}^{+}$ &. & $\mathrm{d}^{+}$ &. & $\mathrm{d}^{1}$ & $\mathrm{II}$ \\
\hline Sphagnum subsecundum & $\mathrm{d}$ &. & $\mathrm{d}^{1}$ & $\mathrm{~d}^{\mathrm{r}}$ &. &. &. &. &. & $\mathrm{II}$ \\
\hline Warnstorfia fluitans &. & $\mathrm{d}$ & $\mathrm{d}$ & $\mathrm{d}$ &. &. &. &. &. & $\mathrm{II}$ \\
\hline Ceratodon purpureus &. & $\mathrm{d}$ &. & $\mathrm{d}$ &. &. &. &. &. & $\mathrm{II}$ \\
\hline Leptodictyum riparium &. &. &. & $\mathrm{ed}$ &. & $\mathrm{ed}$ &. &. &. & II \\
\hline Plagiomnium ellipticum &. &. & $\mathrm{d}$ & $\mathrm{ed}$ &. &. &. &. &. & II \\
\hline
\end{tabular}

Примечание. Виды, отмеченные в одном описании (оп.): сосудистые - Cardamine dentata 1(r); Carex cespitosa 4(+); Carex chordorrhiza 1(+); Cicuta virosa 1(r); Lactuca sibirica 2(r); Melampyrum pratense 2(+); Myosotis caespitosa 8(r); Pinus sylvestris (juv.) 3(r); Ranunculus 
gmelinii 5(r); Ranunculus lingua 2(+); Ranunculus reptans 7(r); Rumex thyrsiflorus 7(r); Senecio tataricus 5(r); Veronica scutellata 2(r); мхи - Amblystegium serpens 3(d); Bryum creberrimum 4(e); Leptobryum pyriforme 4(d); Polytrichum juniperinum 2(dr); Pseudobryum cinclidioides 1(d); Sanionia uncinata 4(e); Sphagnum inundatum 5(d $\left.{ }^{1}\right)$; Sphagnum obtusum 1(d); печеночник - Marchantia polymorpha 5(dr). Для мхов индексами е и d указана ярусная локализация: е - эпифитный ярус (стволики ив), d - напочвенный ярус; ПП (надстрочными цифрами после ярусного индекса) указано только для тех видов, которые удалось надежно распознать в поле. Условные обозначения: оп. $3^{*}$ - голотип (holotypus) субасс. Carici aquatilis-Salicetum lapponum juncetosum filiformis; $\Pi_{2-9}-$ постоянство видов в оп. 2-9; Д.в. - диагностические виды синтаксона; juv. - всходы. Римскими цифрами указан класс постоянства вида в оп. 2-9 (II - 21-40; III - 41-60; IV - 61-80; $\mathrm{V}-81-100 \%$ ); для обильных видов справа от римской цифры надстрочными арабскими цифрами указан квартильный интервал варьирования ПП, переведенный из \% в баллы ПП: +- менее $1 \% ; 1-1-5 ; 2-6-12 ; 3-13-25 ; 4-26-50 ; 5-51-75 ; 6-76-100 \%$. Авторы описаний: В.Н. Тюрин - оп. 1, 3, 5, 7, 9; Г.С. Таран - оп. 2, 4, 6, 8 .

[Note. Species noted in one relevé (rel.) only: vascular plants - Cardamine dentata 1(r); Carex cespitosa 4(+); Carex chordorrhiza 1(+); Cicuta virosa 1(r); Lactuca sibirica 2(r); Melampyrum pratense 2(+); Myosotis caespitosa 8(r); Pinus sylvestris (juv.) 3(r); Ranunculus gmelinii 5(r); Ranunculus lingua $2(+)$; Ranunculus reptans $7(\mathrm{r})$; Rumex thyrsiflorus 7(r); Senecio tataricus $5(\mathrm{r})$; Veronica scutellata 2(r); mosses - Amblystegium serpens 3(d); Bryum creberrimum 4(e); Leptobryum pyriforme 4(d); Polytrichum juniperinum 2(d $\mathrm{d}^{\mathrm{r}}$; Pseudobryum cinclidioides 1(d); Sanionia uncinata 4(e); Sphagnum inundatum 5(d'); Sphagnum obtusum 1(d); liverwort - Marchantia polymorpha 5(dr). For the mosses, layer position is shown by $\mathbf{e}$ and $\mathbf{d}$ indices: $\mathbf{e}$ - epiphyte layer (willow trunks), $\mathbf{d}$ - ground layer. Projective cover is shown (with superlinear marks after layer index) only for species which were safely identified in a field. Symbols: rel. 3* - holotypus of the Carici aquatilis-Salicetum lapponum juncetosum filiformis; $\mathrm{C}_{2-9}$ - species constancy in rel. 2-9; D. s. - diagnostic species of a syntaxon; juv. - seedlings. Species constancy class in rel. 2-9 is shown by Roman numerals (II - 21-40; III - 41-60; IV - 61-80; V $-81-100 \%$ ); for abundant species, quartile intervals of projective cover varying are shown by superline Arabic numerals, they are converted from $\%$ to marks of projective cover: + - less $1 \% ; 1-1-5 ; 2-6-12 ; 3-13-25 ; 4-26-50 ; 5-51-75 ; 6$ $76-100 \%$. Authors of the relevés are VN Tyurin (rel. 1, 3, 5, 7, 9) and GS Taran (rel. 2, 4, 6, 8).]

В верхнем ярусе лопарскоивняков доминирует Salix lapponum, и, несмотря на повторение двух маловодных лет подряд (2010 и 2011 гг.), с III классом постоянства отмечается Carex aquatilis. Оба вида диагностируют асс. Carici aquatilis-Salicetum lapponum. Хорошо выражена комбинация сопутствующих болотных видов: Comarum palustre, Galium palustre, Carex acuta, Carex vesicaria, Naumburgia thyrsiflora и др.

Описания разделяются на две неравные группы: болотную и лугово-болотную. В оп. 1 (см. таблицу) представлен типичный болотный фитоценоз: лопарскоивняк осоково-сабельниково-гипновый. Он развит на приозерном торфянике мощностью 75-80 см, мокром с поверхности; вода по следу не проступает. Торф низинный, хорошо разложившийся, по крайней мере, до 35 см от поверхности (глубина прикопки). Поверхность почвы ровная, изредка отмечаются кочки осок (Carex aquatilis, C. omskiana) высотой 10-20 см.

По составу доминирующих видов этот фитоценоз вполне подобен лопарскоивнякам, описанным в Томской области [5], на Вахе [6] и под Сургутом около водохранилища Сургутской ГРЭС $[8,9]$. В синтаксономическом плане он относится к субасс. Carici aquatilis-Salicetum lapponum typicum Taran 1993. От лопарскоивняков Ваха и севера Томской области оп. 1 и его 
подсургутские аналоги отличаются наличием и заметным обилием Carex lasiocarpa и Carex rostrata. Два последних вида мы принимаем в качестве диагностических для нового варианта типичной субассоциации: var. Carex lasiocarpa.

Лугово-болотные ценозы ивы лопарской (см. таблицу, оп. 2-9) приурочены к минеральным почвам, что придает своеобразие их флористическому составу. На этом основании мы описываем их как новую субассоциацию: Carici aquatilis-Salicetum lapponum juncetosum filiformis Taran, Tyurin et Dyachenko subass. nov. hoc loco. Номенклатурный тип субассоциации (holotypus) - оп. 3 * в таблице: оп. 6 ВТ, 05.09.2011, Сургутский район ХМАО, пойма р. Ягмунъягун, 61¹9'23,9" с.ш., 74²12'16,5" в.д., площадь УП 100 м². Диагностические виды: Juncus filiformis, Gentiana pneumonanthe, Phalaroides arundinacea.

Кустарниковый ярус в ценозах субассоциации неравномерен по высоте и сомкнутости. Среднее ПП Salix lapponum равно 24\%, средняя высота - 1,5 м. В пределах одной УП разница между нижней и верхней высотными группами побегов ивы может составлять 0,4-1,4 м, при этом единичные побеги могут достигать высоты 2,2 (оп. 6, 7), 2,9 (оп. 9) и 3,1 м (оп. 5).

Среднее ОПП травостоя - 48\%. В оп. 2-9 одиннадцать видов отмечены с суммарным ПП 10\% и более: Calamagrostis purpurea - 119, Comarum palustre - 88, Sanguisorba officinalis - 48, Carex acuta - 32, Phalaroides arundinacea - 24, Naumburgia thyrsiflora - 20, Juncus filiformis - 18, Galium palustre - 18, Galium boreale - 12, Carex aquatilis - 10, Agrostis stolonifera - 10. Наиболее гигрофильный вариант субассоциации представлен в оп. 5 и 9 (в травостое доминирует Comarum palustre), наиболее мезофильный - в оп. 8 (преобладает Sanguisorba officinalis). Всего в лугово-болотных лопарскоивняках отмечено 38 видов сосудистых растений, средняя видовая насыщенность сообществ сосудистыми составляет 20,5 вид/а.

Прошлогодняя ветошь на УП отмечается с ПП 30-75\%, и только в оп. 5 она почти полностью перегнила. Поверхность почвы в ценозах субассоциации, как правило, ровная, лишь в оп. 3 отмечены кочки Carex juncella высотой 10-20 см, суммарное ПП которых составило $2 \%$.

Среднее ОПП мхов в оп. 2-9 равно 17\%. Обычный доминант-содоминант яруса D (почва, подстилка, лежащие на почве обгорелые сучья) - Drepanocladus aduncus, реже в этом качестве отмечаются Pohlia nutans (оп. 8), Calliergonella lindbergii и Polytrichum commune (оп. 7), Calliergon giganteum (оп. 5). Характерный вид яруса Е (основания и стволы ив) - Fontinalis hypnoides, который крепится на стволиках ив до высоты 40 см над уровнем почвы (оп. 4, 5, 7).

Средняя видовая насыщенность УП мхами составляет 10,6 вид/а, в том числе по ярусу D - 9,6, по ярусу E - 2,1 вид/а. Всего в оп. 2-9 отмечены 1 вид печеночника (Marchantia polymorpha L.) и 25 видов мхов.

Почвы. На УП 2-9 сделаны прикопки глубиной 53-75 см. Во всех случаях верхний горизонт представлен оторфованной подстилкой толщиной 
от 4 до 11 см. Основная масса корней сосредоточена в верхнем слое почвы глубиной до 14-26 см (см. таблицу). Минеральные горизонты преимущественно песчаные; в верхней части профиля (до глубины 11-52 см) вскрываются легкие суглинки (оп. 2, 5, 6, 8, 9) либо супеси (оп. 3, 7). Изредка (оп. 4) профиль по всей глубине прикопки легкосуглинистый, с песчаными прослойками. Строение почвенного профиля на всех УП соответствует подтипу аллювиальных лугово-болотных оторфованных почв [15].

Ни в одной из прикопок уровень грунтовых вод не был достигнут. Вероятно, это обусловлено низкими уровнями половодий в 2010 и 2011 гг.

Режим затопления. О высоте затопления ягмунъягунских ивняков полыми водами в 2011 г. судили по косвенным признакам: наличию на ветках ив и почве ветоши, принесенной половодьем (оп. 5, 7-9), и высоте крепления на стволиках ив земноводного мха Fontinalis hypnoides. В гигрофильных ценозах ветошь наблюдалась на высотах 40-60 см (оп. 5), 45-60 см (оп. 9), в мезофильном оп. 7 - на высоте $15-50$ см.

В наиболее мезофильном оп. 8 половодная ветошь в виде пятна размером 2-3 м² отмечена на почве и только на краю УП. Следовательно, в оп. 8 на пике затопления полые воды едва покрывали основную поверхность УП и, таким образом, в рельефе разница высот между местообитаниями гигро- и мезофильных ценозов субассоциации равна $60 \mathrm{~cm}$.

Максимальный уровень половодья по гидропосту г. Сургута в 2011 г. составил 619 см, что соответствует уровню 90-95\%-ной обеспеченности [24] и одновременно служит показателем высотно-экологической приуроченности лугово-болотных лопарскоивняков в пойме Ягмунъягуна.

Ареал субассоциации и синтаксономические связи. Два сообщества ивы лопарской, которые можно отнести к субасс. C. a.-S. l. juncetosum filiformis, обнаружены в пойме Оби в 9 км к югу от Сургута [9]. Они сформированы на минеральных почвах невысоких грив, окруженных болотистыми осоковыми (Carex acuta, Carex aquatilis) лугами и осоково-сабельниковыми (Comarum palustre) болотами. Высота ив составляла 1,9-2,0 м, ОПП - 70\%, видовая насыщенность ценозов сосудистыми растениями - 24-28 вид/а. Грунтовые воды под ивняками залегали на глубине 55-60 см.

В синтаксономическом и экологическом отношении субасс. $\boldsymbol{C}$. $\boldsymbol{a} . \boldsymbol{S} \boldsymbol{S} . \boldsymbol{l}$. juncetosum filiformis занимает промежуточное положение между субасс. C. a.-S. l. typicum и асс. Sanguisorbo officinalis-Salicetum rosmarinifoliae Tаran $1993[5,25]$.

Состав ценофлоры. На 9 УП ягмунъягунских лопарскоивняков выявлено 44 вида сосудистых растений, в том числе всходы 2 видов деревьев (Betula pubescens, Pinus sylvestris), 1 вид кустарников (Salix lapponum) и 41 вид трав. Один вид сосудистых (Carex omskiana) ранее [26] для поймы Оби в пределах Сургутского района ХМАО не указывался.

Также отмечены 1 вид печеночника (Marchantia polymorpha L.) и 27 видов мхов. Три вида (Sphagnum centrale, Warnstorfia fluitans, Calliergon gigan- 
teum) на сургутском отрезке обской поймы относятся к числу редких [27, 28]. Один вид (Sphagnum inundatum) для бриофлоры ХМАО приводится впервые.

В ягмунъягунских лопарскоивняках отмечено 8 видов, новых для бриофлоры acc. Carici aquatilis-Salicetum lapponum: Amblystegium serpens, Bryum creberrimum, Ceratodon purpureus, Fontinalis hypnoides, Leskea polycarpa, Polytrichum juniperinum, Sphagnum centrale, Sphagnum inundatum. С учетом ранее полученных результатов [27, 29] бриофлора acc. Carici aquatilis-Salicetum lapponum к настоящему времени насчитывает 4 вида печеночников и 46 видов мхов.

Антропогенные факторы. В 2011 г. ягмунъягунские лопарскоивняки производили впечатление ненарушенных. При этом в большинстве ценозов часто встречались обгорелые пеньки ив, а на почве - горелые сучья.

Пожары в пойме Оби случаются почти ежегодно, а раз в 5-10 лет захватывают обширные площади [30]. Тем не менее за все время нашего изучения обской поймы (1986-2011 гг.) на других ключевых участках следы огня в лопарскоивняках ни разу не отмечались. Полагаем, в данном случае выгорание лопарскоивняков следует объяснять антропогенным воздействием, поскольку данный участок поймы после прокладки к нему насыпной дороги стал легкодоступным для населения.

Пожары происходят весной до прихода полых вод. Вероятность пожаров особенно высока, когда низкое половодье сочетается с сухой и жаркой весенней погодой. Такая ситуация в пойме Ягмунъягуна сложилась в 2005 г., что привело к выгоранию лопарскоивняков на больших площадях.

По наблюдениям В.Н. Тюрина, отрастание ивы лопарской после пожара происходит довольно быстро. Уже к концу вегетационного сезона, в начале которого случился пожар, кусты ивы могут отрасти в высоту на полметра-метр.

Прочие факторы. В 2011 г. лопарскоивняки Ягмунъягунского ключевого полигона были сильно повреждены ивовым листоедом Phratora vulgatissima (L.) (Coleoptera, Chrysomelidae). Столь массовое появление ивового листоеда в пойме Оби наблюдалось нами впервые с 1986 г. Изредка также отмечался листоед Orsodacne cerasi (L.) (Coleoptera, Orsodacnidae).

\section{Заключение}

Acc. Carici aquatilis-Salicetum lapponum Taran 1993 (союз Salicion cinereae Th. Müller et Görs ex Passarge 1961, порядок Salicetalia auritae Doing 1962, класc Alnetea glutinosae Br.-Bl. et Tx. ex Westhoff et al. 1943) - оригинальный, но слабо изученный компонент растительности, отмечаемый в поймах Оби и ее притоков в пределах подзоны средней тайги. Приведенные в статье материалы дают наиболее полное из ныне имеющихся в ботанической литературе описание западносибирских лопарскоивняков в пределах локального ключевого полигона. Одно из типичных местообитаний сообществ ассоциа- 
ции - участки древнего меандрового пояса голоценовой террасы Оби, перемываемой в настоящее время низовыми отрезками обских притоков.

Лопарскоивняки р. Ягмунъягун представлены фитоценозами, которые разделяются на две субассоциации: типичную болотную (Carici aquatilisSalicetum lapponum typicum Taran 1993, вар. Carex lasiocarpa) и нитевидноситниковую лугово-болотную. Последняя описана в качестве нового синтаксона: $\boldsymbol{C}$. a.-S. l. juncetosum filiformis Taran, Tyurin et Dyachenko subass. nov.

Дальнейшая задача наших исследований - выявление границ ареала асс. Carici aquatilis-Salicetum lapponum в Западной Сибири и диапазона ее фитоценотической изменчивости в различных экологических и ландшафтных условиях.

Авторы выражают благодарность канд. биол. наук доценту кафедры экологии А.Н. Панькову (Сургутский государственный университет, г. Сургут) за определение жуков-листоедов.

\section{Лumepamypa}

1. Боч М.С., Смагин В.А. Флора и растительность болот Северо-Запада России и принципы их охраны. СПб. : Гидрометеоиздат, 1993. 225 с.

2. Лапшина Е.Д. Флора болот юго-востока Западной Сибири. Томск : Изд-во Том. ун-та, 2003. $296 \mathrm{c}$.

3. Бронзова Г.Я. Естественные луга в ландшафте таежной поймы р. Васюгана. М. : Издание Института луговой и болотной культуры, 1929. 29 с.

4. Львов Ю.А., Прокопьев Е.П. Растительность поймы р. Тыма // Известия Томского отделения Всесоюзного ботанического общества. Томск, 1973. T. VI. C. 85-98.

5. Таран Г.С. Синтаксономический обзор кустарниковой растительности поймы средней Оби (Александровский отрезок) // Сибирский биологический журнал. 1993. Вып. 6. C. $79-84$.

6. Титов Ю.В., Овечкина Е.С. Растительность поймы реки Вах. Нижневартовск : Изд-во Нижневарт. пед. ин-та, 2000. 123 с.

7. Таран Г.С., Тюрин В.Н. К характеристике флоры и растительности поймы Оби в окрестностях Сургута // Проблемы изучения растительного покрова Сибири : тез. докл. II Рос. науч. конф. Томск : Изд-во Том. ун-та, 2000. С. 140-141.

8. Тюрин В.Н., Титов Ю.В. Эколого-морфологическая характеристика пойменных кустарниковых ивняков Среднего Приобья // Биологические ресурсы и природопользование. Сургут, 2001. Вып. 4. С. 38-51.

9. Таран Г.С., Тюрин В.Н. Очерк растительности поймы Оби у города Сургута // Биологические ресурсы и природопользование. Сургут, 2006. Вып. 9. С. 3-54.

10. Ильина И.С., Лапшина Е.И., Лавренко Н.Н., Мельиер Л.И., Романова Е.А., Богоявленский Б.А., Махно В.Д. Растительный покров Западно-Сибирской равнины. Новосибирск : Наука, 1985. $251 \mathrm{c.}$

11. Лапшина Е.Д. Растительность болот юго-востока Западной Сибири. Новосибирск, 2010. $186 \mathrm{c}$.

12. Малик Л.К. Гидрологические проблемы преобразования природы Западной Сибири. М. : Наука, 1978. 180 с. 
13. Васильев C.B., Седых B.H. Пойма Оби на аэрокосмических снимках. Красноярск : Ин-т леса и древесины им. В.Н. Сукачева СО АН СССР, 1984. 46 с.

14. Обедиентова Г.В. Эрозионные циклы и формирование долины Волги. М. : Наука, 1977. $239 \mathrm{c}$.

15. Классификащия и диагностика почв СССР / сост.: В.В. Егоров, В.М. Фридланд, Е.Н. Иванова, Н.Н. Розов, В.А. Носин, Т.А. Фриев. М. : Колос, 1977. 224 с.

16. Чеботарев А.И. Гидрологический словарь. Л. : Гидрометеоиздат, 1970. 306 с.

17. Зверев А.А. Информационные технологии в исследованиях растительного покрова : учеб. пособие. Томск : ТМЛ-Пресс, 2007. 304 с.

18. Коротков К.О. Леса Валдая. М. : Наука, 1991. 160 с.

19. Weber H.E., Moravec J., Theurillat J.-P. International code of phytosociological nomenclature. $3^{\text {rd }}$ ed. // J. Veg. Sci. 2000. Vol. 11, № 5. P. 739-768. doi: 10.2307/3236580

20. Черепанов C.K. Сосудистые растения России и сопредельных государств (в пределах бывшего СССР). СПб. : Мир и семья-95, 1995. 992 с.

21. Ignatov M.S., Afonina O.M., Ignatova E.A., Abolina A., Akatova T.V., Baisheva E.Z., Bardunov L.V., Baryakina E.A., Belkina O.A., Bezgodov A.G., Boychuk M.A., Cherdantseva V.Ya., Czernyadjeva I.V., Doroshina G.Ya., Dyachenko A.P., Fedosov V.E., Goldberg I.L., Ivanova E.I., Jukoniene I., Kannukene L., Kazanovsky S.G., Kharzinov Z. Kh., Kurbatova L.E., Maksimov A.I., Mamatkulov U.K., Manakyan V.A., Maslovsky O.M., Napreenko M.G., Otnyukova T.N., Partyka L.Ya., Pisarenko O.Yu., Popova N.N., Rykovsky G.F., Tubanova D.Ya., Zheleznova G.V., Zolotov V.I. Check-list of mosses of East Europe and North Asia // Arctoa. 2006. Vol. 15. P. 1-130. doi: 10.15298/arctoa.15.01

22. Таран Г.С. Осиновые и березовые леса поймы Средней Оби (Spiraeo salicifoliaePopuletum tremulae Taran 1993) // Ботанические исследования Сибири и Казахстана. Барнаул, 1998. Вып. 4. С. 82-89.

23. Самойлова Г.С. Соры нижнего течения р. Оби и их хозяйственное использование // География и хозяйство. М., 1958. Вып. 3-4. С. 75-78.

24. Усачев В.Ф., Прокачева В.Г., Бородулин В.В. Оценка динамики озерных льдов, снежного покрова и речных разливов дистанционными средствами (практ. пособие). Л. : Гидрометеоиздат, 1985. 104 с.

25. Таран Г.С. Ивняки и березово-кустарниковые болота с Salix rosmarinifolia L. на Вах-Тымском отрезке поймы Оби // Вестник Оренбургского государственного университета. 2009. № 4. С. 98-103.

26. Таран Г.С., Тюрин В.Н. Флора поймы Оби у города Сургута // Биологические ресурсы и природопользование. Сургут, 2006. Вып. 9. С. 55-79.

27. Таран Г.С., Писаренко О.Ю., Тюрин В.Н. Бриофлора сургутской поймы в пространстве синтаксонов классификации Браун-Бланке // Биологические ресурсы и природопользование. Сургут, 2005. Вып. 8. С. 32-65.

28. Лапшина Е.Д., Писаренко О.Ю. Флора мхов Ханты-Мансийского автономного округа (Западная Сибирь) // Turczaninowia. 2013. Т. 16, № 2. С. 62-80.

29. Таран Г.С., Казановский С.Г., Мульдияров Е.Я. Бриофлора Вах-Тымского отрезка поймы Оби в пространстве растительных сообществ // Биологические ресурсы и природопользование. Сургут, 2006. Вып. 9. С. 80-108.

30. Тюрин В.Н. Пирогенный фактор в пойме Оби (интерпретация данных космосъемки) // Биологические ресурсы и природопользование. Сургут, 2007. Вып. 10. С. 36-41.

Поступила в редакиию 20.04.2016 г.; повторно 12.08.2016 г.; принята 17.08.2016 г.; опубликована 21.09.2016 г. 


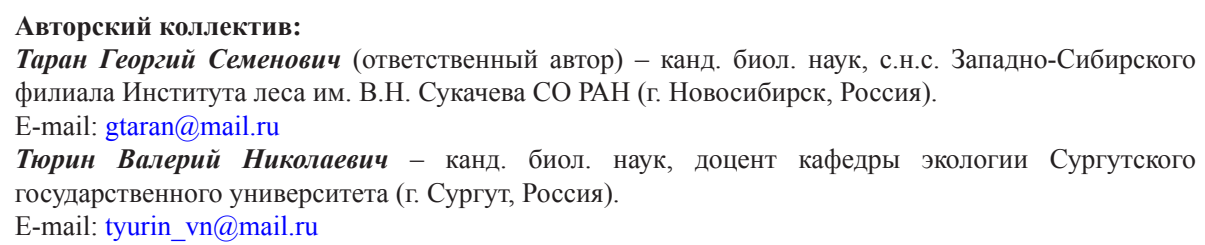

Дьяченко Александр Петрович - д-р биол. наук, профессор кафедры ботаники и методики обучения биологии географо-биологического факультета Уральского государственного педагогического университета (г. Екатеринбург, Россия).

E-mail: eadyach@yandex.ru

Taran GS, Tyurin VN, Dyachenko AP. New locality of downy willow scrubs (Carici aquatilis-Salicetum lapponum Taran 1993, Alnetea glutinosae) in Western Siberia. Vestnik Tomskogo gosudarstvennogo universiteta. Biologiya - Tomsk State University Journal of Biology. 2016;3(35):74-91. doi: 10.17223/19988591/35/5. In Russian, English summary

\title{
Georgy S. Taran', Valery N. Tyurin², Alexander P. Dyachenko ${ }^{3}$
}

\author{
${ }^{1}$ West-Siberian Branch of VN Sukachev Institute of Forest, Siberian Branch of the Russian Academy of \\ Sciences, Novosibirsk, Russian Federation \\ ${ }^{2}$ Surgut State University, Surgut, Russian Federation \\ ${ }^{3}$ Urals State Pedagogical University, Yekaterinburg, Russian Federation
}

\section{New locality of downy willow scrubs (Carici aquatilis-Salicetum lapponum Taran 1993, Alnetea glutinosae) in Western Siberia}

We revealed a new locality of willow scrubs dominated by Salix lapponum L. in the Yagmunyagun River floodplain, $37 \mathrm{~km}$ east of Surgut city, $61^{\circ} 19^{\prime} 23^{\prime \prime} \mathrm{N}, 74^{\circ} 12^{\prime} 01{ }^{\prime \prime} \mathrm{E}$, Surgut district of Khanty-Mansi Autonomous Okrug, Russia. The aim of this paper is to give detailed syntaxonomical and landscape characteristic for the original plant communities scantily reported in geobotanical literature. The study area is located in the middle taiga subzone. In geomorphological respect, the Yagmunyagun floodplain occupies surfaces of the ancient meander belt of the Ob holocene terrace. In hydrological respect, it is a combined floodplain of 3 rivers: the $\mathrm{Ob}$, the Tromyogan and the Yagmunyagun.

The Yagmunyagun key plot area equals 162.4 ha. The main elements of its phytogeomorphological structure are: downy willow scrubs - 43.4\% (70.4 ha), swampy meadows and fens - 30.8\% (50.1 ha), wet birch forests - 7.7\% (12,5 ha); lakes and channels - $14.9 \%$ (24.2 ha); sandy embankments under a road and industrial object $3.2 \%$ (5.2 ha). According to Braun-Blanquet classification, the Yagmunyagun downy willow scrubs belong to the association Carici aquatilis-Salicetum lapponum Taran 1993 (Salicion cinereae Th. Müller et Görs ex Passarge 1961, Salicetalia auritae Doing 1962, Alnetea glutinosae Br.-Bl. et Tx. ex Westhoff et al. 1943). The willow scrubs are divided into 2 subassociations: C. a.-S. l. typicum Taran 1993 (var. Carex lasiocarpa) and Carici aquatilis-Salicetum lapponum juncetosum filiformis Taran, Tyurin et Dyachenko subass. nov.; diagnostic species of the latter are Juncus filiformis, Gentiana pneumonanthe and Phalaroides arundinacea. The willow scrubs of Carici aquatilisSalicetum lapponum juncetosum filiformis are formed on the meadow-boggy peaty soils and located on flood levels of $90-95 \%$ probability. Mean willow height in $\boldsymbol{C}$. a. $-\boldsymbol{S}$. l. juncetosum filiformis coenoses is $1.5 \mathrm{~m}$, mean total projective cover of the willow $24 \%$, field layer $-48 \%$ and ground-layer mosses $-17 \%$. Mean species saturation of the coenoses with vascular plants is 20.5 , with mosses - 10.6 species per $100 \mathrm{~m}^{2}$. In field 
layer of 8 relevés of $\boldsymbol{C}$. a. $\mathbf{S}$. l. juncetosum filiformis coenoses, 11 species of vascular plants are noted with the greatest summary projective cover: Calamagrostis purpurea 119, Comarum palustre - 88, Sanguisorba officinalis - 48, Carex acuta - 32, Phalaroides arundinacea -24, Naumburgia thyrsiflora - 20, Juncus filiformis - 18, Galium palustre 18, Galium boreale - 12, Carex aquatilis - 10, Agrostis stolonifera - 10\%. The most abundant species in ground layer of the subassociation coenoses are Drepanocladus aduncus, Pohlia nutans, Calliergonella lindbergii, Polytrichum commune and Calliergon giganteum. In all 9 relevés of the Yagmunyagun downy willow scrubs, we revealed 44 species of vascular plants, 1 species of liverworts and 27 species of mosses, including Sphagnum inundatum, new for moss flora of Khanty-Mansi Autonomous Okrug. Eight moss species (Amblystegium serpens, Bryum creberrimum, Ceratodon purpureus, Fontinalis hypnoides, Leskea polycarpa, Polytrichum juniperinum, Sphagnum centrale, Sphagnum inundatum) found in the Yagmunyagun downy willow scrubs are new for bryoflora of Carici aquatilis-Salicetum lapponum. Taking into account our results obtained in Western Siberia earlier, now Carici aquatilis-Salicetum lapponum bryoflora numbers 4 species of liverworts and 46 ones of mosses.

Acknowledgments: Cand. Sci. (Biol.), Ass. Prof. AN Pankov (Department of Ecology, Surgut State University, Surgut, Russia) for defining Chrysomelidae.

The article contains 2 Figures, 1 Table, 30 References.

Key words: willow scrubs; Salix lapponum; bryoflora; syntaxonomy, floodplain vegetation; middle taiga subzone.

\section{References}

1. Botch MS, Smagin VA. Flora i rastitel'nost' bolot Severo-Zapada Rossii i printsipy ikh okhrany [Flora and vegetation of mires in the North-West of Russia and principles of their protection]. St. Petersburg: Gidrometeoizdat; 1993. 224 p. In Russian

2. Lapshina ED. Flora bolot yugo-vostoka Zapadnoy Sibiri [Flora of mires of the south-east of Western Siberia]. Tomsk: Tomsk State University Press; 2003. 296 p. In Russian

3. Bronzova GYa. Yestestvennyye luga $v$ landshafte tayozhnoy poymy Vasyugana [Natural meadows in the landscape of taiga floodplain of the Vasyugan]. Moscow: Institute of Meadow and Mire Culture Press; 1929. 29 p. In Russian

4. L'vov YuA, Prokopiev EP. Rastitel'nost' poymy reki Tyma [Vegetation of the Tym River floodplain]. Tomsk: Izvestiya Tomskogo otdeleniya Vsesoyuznogo botanicheskogo obshchestva [Proceedings of the Tomsk Branch of the All-Union Botanical Society]. 1973;6:85-98. In Russian

5. Taran GS. Syntaxonomical survey of shrub vegetation of middle Ob flood-plain (Aleksandrovskoye piece). Sibirskiy Biologicheskiy Zhurnal - Siberian Journal of Biology. 1993;6:79-84. In Russian

6. Titov YuV, Ovechkina ES. Rastitel'nost' poymy reki Vakh [Vegetation of the Vakh River floodplain]. Nizhnevartovsk: Nizhnevartovsk Pedagogical Institute Press; 2000. 123 p. In Russian

7. Taran GS, Tyurin VN. K kharakteristike flory i rastitel'nosti poymy Obi v okrestnostyakh Surguta [On the characteristic of the Ob floodplain flora and vegetation in the vicinities of Surgut]. In: Problemy izucheniya rastitel'nogo pokrova Sibiri [Problems of study of vegetation cover of Siberia. Abstracts of the 2 nd Russian Sci. Conf]. Tomsk: Tomsk State University Press; 2000. pp. 140-141. In Russian

8. Tyurin VN, Titov YuV. Ecological and morphological characteristics of the flooded willow beds in the middle $\mathrm{Ob}$. In: Biologicheskie resursy i prirodopol'zovanie [Biological resources and nature anagement. Proc. of Sci.]. Surgut: Defis Publ.; 2001;4:38-51. In Russian 
9. Taran GS, Tyurin VN. Review of the Ob floodplain vegetation near Surgut. In: Biologicheskie resursy i prirodopol'zovanie [Biological resources and nature anagement. Proc. of Sci.]. Surgut: Defis Publ.; 2006;9:3-54. In Russian

10. Ilyina IS, Lapshina EI, Lavrenko NN, Mel'tser LI, Romanova EA, Bogoyavlenskiy BA, Makhno VD. Rastitel'nyy pokrov Zapadno-Sibirskoy ravniny [Vegetation cover of the WestSiberian plain]. Novosibirsk: Novosibirsk State University Publ.; 1985. 251 p. In Russian

11. Lapshina ED. Rastitel'nost' bolot yugo-vostoka Zapadnoy Sibiri [Vegetation of mires of the south-east of Western Siberia]. Novosibirsk: Novosibirsk State University Publ.; 2003. 296 p. In Russian

12. Malik LK. Gidrologicheskiye problemy preobrazovaniya prirody Zapadnoy Sibiri [Hydrological problems of transformation of nature of Western Siberia]. Moscow: Nauka Publ.; 1978. 180 p. In Russian

13. Vasiliev SV, Sedykh VN. Poyma Obi na aerokosmicheskikh snimkakh [The Ob floodplain in aerial and space views]. Krasnoyarsk: Institute of Forest and Wood of the Siberian Branch of the Academy of Sciences of the USSR; 1984. 46 p. In Russian

14. Obedientova GV. Erozionnyye tsikly i formirovaniye doliny Volgi [Erosion cycles and the Volga valley forming]. Moscow: Nauka Publ.; 1977. 239 p. In Russian

15. Klassifikatsiya i diagnostika pochv SSSR [Classification and diagnostics of soils of the USSR]. Egorov VV, Fridland VM, Ivanova EN, Rozov NN, Nosin VA, Friev TA, compilers. Moscow: Kolos Publ.; 1977. 224 p. In Russian

16. Chebotarev AI. Gidrologicheskiy slovar' [Hydrological glossary]. Leningrad: Gidrometeoizdat; 1970. 306 p. In Russian

17. Zverev AA. Informatsionnye tekhnologii $\mathrm{v}$ issledovaniyakh rastitel'nogo pokrova [Information technologies in researches of vegetative cover: Text-book]. Tomsk: TML Press Publ.; 2007. 304 p. In Russian

18. Korotkov KO. Valday forests. Moscow: Nauka Publ.; 1991. 160 p. In Russian

19. Weber HE, Moravec J, Theurillat J.-P. International code of phytosociological nomenclature. $3^{\text {rd }}$ ed. J. Veg. Sci. 2000;11(5):739-768. doi: 10.2307/3236580

20. Czerepanov SK. Sosudistye rasteniya Rossii i sopredel'nykh gosudarstv (v predelakh byvshego SSSR) [Vascular plants of Russia and adjacent states (within the limits of the former USSR)]. Moscow: World and Family-95 Ltd.; 1995. 992 p. In Russian

21. Ignatov MS, Afonina OM, Ignatova EA, Abolina A, Akatova TV, Baisheva EZ, Bardunov LV, Baryakina EA, Belkina OA, Bezgodov AG, Boychuk MA, Cherdantseva VYa, Czernyadjeva IV, Doroshina GYa, Dyachenko AP, Fedosov VE, Goldberg IL, Ivanova EI, Jukoniene I, Kannukene L, Kazanovsky SG, Kharzinov ZKh, Kurbatova LE, Maksimov AI, Mamatkulov UK, Manakyan VA, Maslovsky OM, Napreenko MG, Otnyukova TN, Partyka LYa, Pisarenko OYu, Popova NN, Rykovsky GF, Tubanova DYa, Zheleznova GV, Zolotov VI. Check-list of mosses of East Europe and North Asia. Arctoa. 2006;15:1-130. doi: 10.15298/arctoa.15.01

22. Taran GS. Asp and birch forests of middle Ob floodplain (Spiraeo salicifoliae-Populetum tremulae Taran 1993). In: Botanicheskie issledovaniya Sibiri i Kazakhstana [Botanical Investigations of Siberia and Kazakhstan]. Kypriyanov AN, editor. Barnaul: Altay State University Publ.; 1998;4:82-89. In Russian

23. Samoylova GS. Sors of the Ob River lower course and their economic management. In: Geografiya i khozyaystvo [Geography and Economy]. 1958:3-4;75-78. In Russian

24. Usachev VF, Prokacheva VG, Borodulin VV. Otsenka dinamiki ozernykh l'dov, snezhnogo pokrova i rechnykh razlivov distantsionnymi sredstvami [Evaluation of dynamics of lake ice, snow cover and river floods by remote means]. Leningrad: Gidrometeoizdat; 1985. 104 p. In Russian

25. Taran GS. Willow stands and birch-shrub bogs with Salix rosmarinifolia L. on Vakh-Tym section of the Ob River floodplain. Vestnik Orenburgskogo gosudarstvennogo universitetaBulletin of Orenburg State University. 2009:4;98-103. In Russian 
26. Taran GS, Tyurin VN. Flora of Ob River floodplain near Surgut city. In: Biologicheskie resursy i prirodopol'zovanie [Biological resources and nature management. Proc. of Sci.]. Surgut: Defis Publ.; 2006;9:55-79. In Russian

27. Taran GS, Pisarenko OYu, Tyurin VN. Bryoflora of Ob floodplain in Surgut city vicinities in space of Braun-Blanquet classification syntaxa. In: Biologicheskie resursy $i$ prirodopol'zovanie [Biological resources and nature management. Proc. of Sci.]. Surgut: Defis Publ.; 2005;8:32-65. In Russian

28. Lapshina ED, Pisarenko OYu. Moss flora of the Khanty-Mansiysk Autonomous District (West Siberia). Turczaninowia. 2013;16(2):62-80.

29. Taran GS, Kazanovskiy SG, Mul'diyarov EYa. Bryoflora of Vakh-Tym section of the $\mathrm{Ob}$ River floodplain in space of plant communities. In: Biologicheskie resursy $i$ prirodopol'zovanie [Biological resources and nature management. Proc. of Sci.]. Surgut: Defis Publ.; 2006;9:80-108. In Russian

30. Tyurin VN. Pyrogenic factor in the Ob floodplain (interpretation of data from space. In: Biologicheskie resursy i prirodopol'zovanie [Biological resources and nature management. Proc. of Sci.]. Surgut: Defis Publ.; 2007;10:36-41. In Russian

Received 20 April 2016; Revised 12 August 2016; Accepted 17 August 2016; Published 21 September 2016

\footnotetext{
Author info:

Taran Georgy S, Corresponding Author, Cand. Sci. (Biol.), Senior Researcher, West-Siberian Branch of VN Sukachev Institute of Forest, Siberian Branch of the Russian Academy of Sciences, 100/1 Zhukovskogo Str., Novosibirsk 630082, Russian Federation.

E-mail: gtaran@mail.ru

Tyurin Valery N, Cand. Sci. (Biol.), Ass. Prof. of Department of Ecology, Surgut State University, 22 Energetikov Str., Surgut 628400, Russian Federation.

E-mail: tyurin_vn@mail.ru

Dyachenko Alexander P, Dr. Sci. (Biol.), Professor of Department of Botany and Methods of Teaching Biology, Urals State Pedagogical University, 26 Kosmonavtov Ave., Yekaterinburg 620017, Russian Federation.

E-mail: eadyach@yandex.ru
} 